\title{
A Perspective on How Coronavirus Commenced and its Disruptive Impact on Global Economy
}

\section{Manchanda $\mathrm{P}^{1}$ and Jaiswal $\mathrm{AK}^{2 *}$}

${ }^{1}$ Research Associate, ASER Centre, Pratham Education Foundation, India

${ }^{2} \mathrm{Ph}$.D. Scholar, International Institute for Population Sciences, India

\section{Perspective}

Volume 4 Issue 3

Received Date: May 06, 2021

Published Date: May 28, 2021

DOI: $10.23880 /$ jqhe-16000226

Population Sciences, Mumbai, India, Email: ajitjaiswal20@gmail.com

\section{Abstract}

This COVID-19 pandemic has a colossal impact on individuals as well as society. The discipline of health economics has grown significantly in recent years and new methodologies and techniques have been developed to evaluate the economic burden of the diseases. Amid the lockdown, scarce resources and increasing medical costs have highlighted the need to quantify the burden of COVID-19 on the healthcare system and thus the present study tried to make accurate economic assessments of the impact of this disease. The outbreak of the COVID-19 pandemic is an unprecedented shock to the economies globally. With the prolonged nation-wide lockdown, global economic downturn, and imbalances of demand and supply sides, the global economy is facing an extended period of slowdown, which is likely to be existing for a while now. The magnitude of the economic impact will depend upon the duration and severity of this global health crisis and the manner in which the situation unfolds once the economy starts to recover.

Keywords: Coronavirus; COVID-19; Economic Impact; Global Economy

\section{Introduction}

On December 31, 2019, the WHO Office in-country, China has reported a cluster of pneumonia cases of an unknown cause that would later be identified as severe acute respiratory syndrome coronavirus 2 (SARS-CoV-2) [13]. In recognition of the widespread global transmission of COVID-19, the World Health Organization declared COVID-19 to be a pandemic on March 11, 2020 [4].

As on, 27th May, 2020, the total number of COVID-19 infections has risen above 5,595,091 globally with 350,547 deaths. USA has the highest number of confirmed cases standing at $(1,681,418)$, followed by Brazil $(391,222)$, Russia $(362,342)$ and United Kingdom $(266,599)$. Meanwhile, the
USA has lost a huge number of people to the virus. Its figures stand at $(98,929)$ followed by United Kingdom $(37,130)$, Italy $(32,955)$, and France $(28,533)[5]$.

This COVID-19 pandemic has a colossal impact on individuals as well as the society. Amid the lockdown, scarce resources and an increasing medical costs have highlighted the need to quantify the burden of COVID-19 on healthcare system and thus the present study trying to make accurate economic assessments of the impact of this disease. A number of studies have discussed about the huge economic impact a pandemic could have. Such as:

In a study by Cooper, et al. [6], the author argued that supply chains would break down, financial markets, real 
estate and home decorating and furnishing companies would be disrupted, "trade disruptions would shutter manufacturing plants," and that "depending on its length and severity, its economic impact could be compared, at least for a short while, to the Great Depression of the 1930s.". Further Cooper, et al. [7] predicts that a mild pandemic would reduce the global Gross Domestic Product (GDP) by 2 per cent while a severe pandemic would reduce the GDP by 6 per cent.

McKibbin, et al. [8] estimate a global GDP and gave their arguments in a different way. As the scale of the pandemic surges, consequently, so do the economic costs. They considered four possible scenarios of it, viz. "Mild" (e.g., Hong-Kong flu of 1968-69), "Moderate" (e.g. Asian flu of 1957), "Severe" (e.g. Spanish flu of 1918), and "Ultra" (worse than the Spanish flu). They estimated that even if a mild pandemic takes place then it can cost the world 1.4 million lives and it may cost the global economy a significant consequence close to 0.8 per cent of GDP.

In another study done by the U.S. Congressional Budget Office (CBO) in 2005 [9], based on an analysis of past pandemics, CBO has devised two scenarios to outline the possible economic effects. The first, in the severe-pandemic scenario, real GDP would be about 4-1/4 per cent lower over the subsequent year, while the second, in mild-pandemic scenario, real GDP may reduce by a modest amount, about 1 per cent only relative to what would have happened without a pandemic, but probably would not cause a recession and might not be distinguishable from the normal variation in economic activity.

According to a document developed Avian Flu Working (AFW) group in 2006, to present the distillation of common elements of business continuity planning for financial systems, they argue that a severe pandemic could result a sharp but short-term effect on global economy. They claim that risk premia could rise, asset markets could be negatively affected and that high rates of absenteeism could cause disruption to the global financial system, including clearing and payment systems [10].

In a study of Asian Development Bank report, Bloom and others had argued about the two scenarios with a relatively mild pandemic could reduce Asian GDP by between 2.6 and 6.8 per cent [11].

There is a simulation study by Kennedy and others discussed about the pathways through which a pandemic might affect the Australian economy. They estimated that in short-term effect GDP might contract by over 5 per cent in the year following an influenza outbreak while in the medium term, consumption and GDP growth both recovered by the end of the second year [12].
In New Zealand, treasury examined economic impact in the country on the basis of attack rate and case-fatality rate and found that in a scenario of severe pandemic, the GDP could reduce by 5 to 10 per cent in the year of pandemic [13].

Another study was done on possible macroeconomic effects of a pandemic, taking place in Europe in 2006. In this study, Jonung, et al. [14] estimated the costs of a pandemic, using the various mortality and morbidity based assumptions, and concluded that for the first year of a pandemic that is for 2006, a supply effect of 1.1 per cent of GDP and a demand effect of 0.5 per cent, calculating a fall in GDP of 1.6 per cent.

In Indian context, a few studies have exposed the socio-economic consequences of pandemic, like influenza or others. Most of the literatures have focused broadly on epidemiological and demographic aspects of the pandemics, for instance, they found how the mortality numbers got increased in such a short time-period; the reasons behind areas which were more prone to influenza than others $[15,16]$. It was colonial administration in India, when a pandemic like influenza took place in 1918-19. Literature posits that vast export of wheat and other staple food items occasioned by war, in accompany with apparent shortage of rainfall contribute to the scarcity of agricultural produce which triggered the economic depression in India $[17,18]$.

The discipline of health economics has grown significantly in recent years and new methodologies and techniques have been developed to evaluate the economic burden of the diseases. The economic analysis of diseases can be divided in two phases, (a). Descriptive phase, in which the burden of the disease; and (b). Analytical phase, in which the cost and consequences of interventions for limiting and eradicating the burden of illness are estimated and evaluated. The cost of any illness is the sum of direct, indirect and intangible costs. A cost-benefit study done by Levy of influenza vaccination for the employed adult population in France in 1985, and it was found that estimated indirect cost could be between 1.5 and 2.0 times higher than direct costs [19].

- Direct Costs: These are attributable to patient care or treatment in hospitals or rehabilitation centers. It has been documented that, the highest hospitalization rate occurs among younger and elderly age-groups because these population are worst affected with COVID-19 $[20,21]$. Similarly, Influenza virus did not kill healthy children and adults [22], but severe complications and deaths occurred, especially in infants, the elderly, and individuals with chronic health conditions, such as cardiac disease, respiratory disease, or immunosuppression. Among the most severe influenza complications is pneumonia, typically associated with secondary or coinfection with bacterial agents $[23,24]$. 
- Indirect Costs: It is related to all of the additional costs, which are associated with either being ill or the economic impact of behavior adopted to avoid becoming diseased. These costs incorporate the lost potential productivity resulting from worker's absenteeism due to morbidity and mortality, spurred by fear of contracting the disease including the loss of wages as well as opportunity costs. In a French cost-benefit study indirect costs was estimated to be accounted for 80-90 per cent of the total costs and stem largely from absenteeism and the loss of work productivity [19].

- Intangible Costs: Health economics related studies also consider the intangible costs which generally, cannot be measured directly in monetary terms. These costs are utilized to quantifying the conditions of certain medical treatments and measures, include impaired functional status of patients and reduced quality of life for both patients and their families, pain, joy etc. Sometimes, these medical conditions may have adverse effects on the quality of life, such as, loss of leisure time and inability to undertake normal daily activities, are also some other important factors that should not be underestimated.

\section{- Prime reasons behind the spread of the COVID-19}

Globally, in any case, the coronavirus was introduced through globalization-triggered international alignment and incubated through political and religious processes. We will draw a few examples from corona-affected countries, as to illustrate that how this social distancing is actually working in the periphery. A major increase in the pandemic in South Korea was due to community spread; when the controversies started doing rounds about Shincheonji church of Jesus with a personality cult centered on around 88-year-old Lee Manhee, who identified as a messianic savior. This cult facilitated the transmission of the disease from Wuhan to South Korea because of the frequent travel among its followers. Singapore too is facing a similar surge in community spread of the novel coronavirus (nCoV) [25].

Iran became a prime COVID-19 hot spot in West Asia due to a unique set of circumstances. Amid its long-running conflict with the US, Iran has started its ties with China due to economic sanctions imposed by the U.S.- led western countries. The sanctions have led to a sharp decline in Iran's economy, pushing the value of its currency to the lowest in its records and soaring high its annual inflation rate, driving away foreign investors, and prompting protests. And, a strong ties between Beijing and Tehran have been evident in recent days for business purposes. The very first COVID-19 patient in Iran was also an Iranian trader, who made a business trip to Wuhan. The main two initial hub of disease transmission was Qom, a popular pilgrimage centre for Shiite Muslims and the other one was the Iranian Parliament, which has a strong connections with Qom. Social distancing was contrary to popular forms of social greeting in Iran particularly among the ruling elite [25].

The onset of the COVID-19 epidemic in India and Sri Lanka has a lot to do with the travel and tourism. For instance, on 4th March, 2020, in India, twenty-two new cases came to light, including 14 Italian tourists who were travelling as a group in northern India tested positive for COVID-19 [26]; also Sri Lanka on 11th March, 2020 announced its first coronavirus case, a 52-year-old tour guide who had come in contact with a group of Italian tourists [27]. Similarly, the US also reported the very first case on 19th January, 2020, when a 35-year-old man presented to an urgent care clinic in Snohomish County, Washington. The patient disclosed that he had returned to Washington State on January 15 after traveling to visit his family in Wuhan, China.

So, this virus moved under the radar swiftly in February and March, because few cities or states of any country had adequate surveillance systems and testing. Emergency rooms were very busy in preparation for the predicted onslaught and importantly, there wasn't enough time as well tools to verify infections on the fly [28].

\section{- Social Measures taken by the governments}

Again the world has the situation similar to the "Spanish Flu" pandemic in 1918, which affected around 500 million and claimed the lives of around 10-15 millions. Now, around a century later, when the world has supposedly made massive progress and our scientists have focused on higher order problems- like blurring the boundaries between the real and virtual worlds.

In response to the coronavirus pandemic, several countries took partial or complete lockdowns as an effective measure to flatten the curve of the infection. These lockdowns meant restricting citizens to their houses, shutting down businesses and putting an end to any kind of economic activity. As the governments across all the countries realizing the repercussion effects of extended period of lockdowns, some countries have lifted restrictions on economic activities and gradually restarted their economies with some conditions applicable.

The governments took some major initiatives such as screening and suspending the major community events, and announced closure of educational institutes and hygiene/ disinfectant measures at airports and hospitals. In the continuum of this, to curb the spread of diseases governments also ordered for the closure of all non-strategic businesses. Only those businesses identified as vital for maintaining the country's supply chain will remain open during this period. 
Supermarkets, pharmacies, banking services and other public services such as transport will remain open.

\section{- How lockdown affects the global economy}

The pandemics adversely impact economy globally. As per the analysis by the UN Department of Economic and Social affairs (DESA), the COVID-19 pandemic could contract the global economy by 0.9 per cent in 2020 , as compared to the previous forecast of 2.5 per cent growth. If the restrictions on international trade prolongs further, it will lead to the contraction of world economies at a much higher rate.

The worldwide outbreak of COVID-19 has impacted travel and tourism like no other event before in history. This disease has brought the world to a standstill of uncertainty. With international trade being closed, the mobility of people and tourism industry have come to an indefinite halt. Extended restrictions on international travel could severely impact developing economies that are highly dependent on tourism as a source of revenue. A much larger proportion of the global tourism sector is contributed by the Small- and medium-sized enterprises (SMEs), around 80 per, which employs about 123 million people all across the globe. Worldwide, millions of workers are facing the risk of losing their jobs [29]. According to a comprehensive landmark report of World Tourism Organization (UNWTO), almost all global destinations have imposed restrictions on travel since January 2020. Because of this, tourism has been the worst affected of all major economic sectors. According to UNWTO Secretary-General Zurab Pololikashvili: "The world is facing an unprecedented health and economic crisis. Tourism has been hit hard, with millions of jobs at risk in one of the most labor-intensive sectors of the economy." International tourism fell down 22 per cent during the first quarter of 2020 and it is estimated that it could decline by $60-80$ per cent over the entire year. Around 67 million fewer international tourists up to March translates into US $\$ 80$ billion loss in exports [30].

In India, the apex sectoral body of Federation of Associations in Indian Tourism \& Hospitality (FAITH) has forecasted loss in India's tourism sector to Rs. 10 lakh crore. FAITH said in a letter to Narendra Modi that around 3.8 crore people could get unemployed in the tourism and hospitality sector, which is around 70 per cent of the total 5.5 crore workforce [31,32].

As per estimates released by the IMF, advanced economies like the US, the UK, Germany, Italy and Spain are expected to contract this year by 5.9, 6.5, 7.0, 9.1 and 8 per cent respectively. On the other hand, developing economies like China and India are expected to grow by merely 1.0 and 1.2 per cent respectively. A study by IMF exploring the aftermath of pandemics shows that major epidemics in this century have not only gave rise to income inequality but also the scenario of job loss harming those workers with basic levels of education, while the employment of those with higher levels of education is hardly affected [33]. Workers who are in part-time and temporary jobs without any social safety net are the most vulnerable group which is at a high stake of bearing the repercussion effects of full or partial lockdowns. Commonly known as informal workers are on the cusp of income and loss of livelihoods.

To control the spread of the COVID-19 pandemic, the central government of India had initially put together some national guidelines that were issued to regulate the lockdown. A classification of regions segregated into different colour zones allowing or prohibiting certain activities according to each zone. The central government allowed the state governments to retain their powers to regulate the lockdown situation as per zone-based needs approach. State governments can decide what is permissible or not. What does this imply for today's modern economic society? Most of the things we use in our households come from the market, which is produced and procured to the market by someone else- farmers, workers and producers are the key supply-side stakeholders in this market system. We, as buyers, exchange money to exchange for the good(s) we need from the market. For this market system to work efficiently, there has to be an equilibrium between demand and supply for the goods offered. Against this mechanism, when the lockdown is in place all over, people cannot go to their respective workplaces to earn money, which is a medium to exchange goods in the market, and so production comes to a halt. Certain essential goods are allowed to be produced, while other workers are restricted from going to work.

In India, there is a large section of workers, commonly known as informal workers, who account for more than 90 per cent in the economy [34]. For many of them, they earn bare minimum which hardly gives them any opportunity to save for their difficult times, like these. So, now that their incomes have stopped flowing in, their consumption too falls. As these workers are largely migrants from different parts of India, earning their livelihoods in cities now have started moving back to their "homes" in the hope that they will get at least food to survive and they will be able to keep their families and themselves safe from both the pandemic and this "workless" crisis-like situation.

In order to address the issue of safety nets for these informal workers, recently, Indian government has announced an ambiguous COVID-19 economic package to revive its stalled economy and make India self-reliant. Financial experts and economists have already been debating over the government's economy revival package by many pointing out that this package is about 1 per cent of the 
GDP, as opposed to the government's '10 per cent of the GDP' claim. With the declining demand and low investment in the businesses mean stalling revenue and the government would need to invest to give a boost to the economy. The National Council of Applied Economic Research (NCAER) estimates that India requires 3- 5 per cent of additional public expenditure to bring its economy back to positive growth [35]. The appropriate measures from multiple channels need to be collectively applied to revive the economy. It could be, for instance, lending credits for longer period of time to MSMEs and street vendors. This is not only a health crisis but a humanitarian crisis, in general, where death toll is no longer limited to COVID-19 pandemic but also possible survival related as well. Migrants are getting killed in accidents while walking thousands of kilometers all their way to their homes with their families in the search of basic survival.

\section{Conclusion}

The outbreak of the COVID-19 pandemic is an unprecedented shock to the economies globally. With the prolonged nation-wide lockdown, global economic downturn and imbalances of demand and supply sides, global economy is facing an extended period of slowdown, which is likely to be existing for a while now. The magnitude of the economic impact will depend upon the duration and severity of this global health crisis and the manner in which the situation unfolds once the economy starts to recover.

Ethics Statement: This paper is a perspective so it did not need ethical consideration.

\section{Acknowledgement}

The authors are thankful to Miss. Aditi and Mr. Mrinmoy Pratim Bharadqaz for their feedbacks that enrich this paper technically.

\section{Conflict of Interest}

The author has no conflicts of interest to declare for this study.

\section{Funding}

None

\section{References}

1. (2020) World Health Organization (WHOa) Pneumonia of unknown cause-China.

2. (2020) World Health Organization (WHOb) Novel Coronavirus-China.
3. Zhu N, Zhang D, Wang W, Li X, Yang B, et al. (2020) A novel coronavirus from patients with pneumonia in China, 2019. New England Journal of Medicine 382: 727733.

4. (2020) World Health Organization (WHOc) Rolling updates on coronavirus disease (COVID-19).

5. JHU CCSE (2020) Novel Coronavirus (COVID-19) Cases Data.

6. Cooper Sherry (2005) Don't Fear or Panic: An Economist's View of Pandemic Flu. Bank of Montreal Special Report

7. Cooper Sherry (2006) The Avian Flu Crisis: An Economic Update. Bank of Montreal Special Report.

8. McKibbin Warwick J, Sidorenko Alexandra A (2006) Global Macroeconomic Consequences of Pandemic Influenza. Lowry Institute Analysis pp: 1-81.

9. Congress US (2005) A Potential Influenza Pandemic: Possible Macroeconomic Effects and Policy Issues. Congressional Budget Office Assessment.

10. Avian Flu Working Group. (2006) The global economic and financial impact of an avian flu pandemic and the role of the IMF In: The global economic and financial impact of an avian flu pandemic and the role of the IMF. Avian Flu Working Group.

11. Erik B, Vincent DW, Jose CS, Mary J (2005) Potential Economic Impact of an Avian Flu Pandemic on Asia" Asian Development Bank ERD Policy Brief pp: 42.

12. Steven K, Jim T, Petar V (2006) A Primer on the Macroeconomic Effects of an Influenza Pandemic." Australian Treasury Working Paper 2006-01.

13. Douglas J, Szeto K, Buckle B (2006) Impacts of a Potential Influenza Pandemic on New Zealand's Macroeconomy. New Zealand Treasury.

14. Jonung L, Roeger W (2006) The macroeconomic effects of a pandemic in Europe-A model-based assessment.

15. Chandra S, Kassens Noor E, Kuljanin G, Vertalka J (2013) A geographic analysis of population density thresholds in the influenza pandemic of 1918-19. International journal of health geographics 12(1): 9 .

16. Hill K (2008) Influenza in India 1918: epicenter of an epidemic.

17. Bagchi AK (2014) Indian economy and society during world war one. Social scientist 42(7/8): 5-27.

18. Harnetty P (2001) The famine that never was: Christian 
missionaries in India 1918-1919. The Historian 63(3): 555-575.

19. Levy E (1996) French economic evaluations of influenza and influenza vaccination. Pharmacoeconomics 9(3): 62-66.

20. Dutta SS (2020) More than 100 under 30 years died of Covid-19 in India so far: Centre. The New Indian Express.

21. Dey S (2020) Share of Under-60 age group in India's COVID deaths rises. The Times of India.

22. Monto AS (2008) Epidemiology of influenza. Vaccine 26: D45-D48.

23. Morens DM, Taubenberger JK, Fauci AS (2008) Predominant role of bacterial pneumonia as a cause of death in pandemic influenza: implications for pandemic influenza preparedness. The Journal of infectious diseases 198(7): 962-970.

24. Perrotta DM, Decker M, Glezen WP (1985) Acute respiratory disease hospitalizations as a measure of impact of epidemic influenza. American journal of epidemiology 122(3): 468-476.

25. Silva TK (2020) Beyond social distancing to fight COVID-19. The Hindu.

26. Perappadan BS (2020) COVID-19| 6 members of Delhi patient's family test positive for coronavirus. The Hindu.

27. PTIc (2020) Sri Lanka Reports First Coronavirus Case. News 18.

28. Carey B, Glanz J (2020) Hidden outbreaks spread through U.S. cities far earlier than Americans knew, estimates say. The Economic Times.

29. UN DESA (2020) COVID-19: Disrupting lives, economies and societies pp: 136.

30. (2020) United Nation World Tourism Organization (UN WTO) report New Release International Tourist Numbers Could Fall 60-80\% IN 2020. Spain, Madrid.

31. PTIa (2020) Coronavirus impact may render $3.8 \mathrm{cr}$ people jobless in tourism, hospitality: Federation of Associations (FAITH). Financial Express.

32. PTIb (2020). Covid-19 impact: Loss forecast for India's tourism sector doubles to Rs 10 lakh crore, says FAITH. Financial Express.

33. Furceri D (2020) How Pandemics leave the poor even farther behind.

34. NSSO (2014) Employment and Unemployment Situation in India, NSS 68th Round.

35. NCAER (2020) Quarterly review of the Economy: Q12020 in Coronavirus times (Press release). 